\title{
Allometric growth of two species of Ephemeroptera from Neotropical mountains streams
}

\author{
Gabriel de Paula Paciencia ${ }^{1,2}$, Pitágoras da Conceição Bispo ${ }^{1 *}$ and Sara Sanches Cortezzi ${ }^{1}$ \\ ${ }^{1}$ Laboratório de Biologia Aquática, Departamento de Ciências Biológicas, Faculdade de Ciências e Letras de Assis, Universidade \\ Estadual Paulista, Av. Dom Antônio, 2100, Parque Universitário, CEP 19806-900 Assis, SP, Brazil \\ 2 PPG em Entomologia, Departamento de Biologia, Faculdade de Filosofia, Ciências e Letras de Ribeirão Preto, Universidade de São \\ Paulo, Av. dos Bandeirantes, 3900, Monte Alegre, CEP 14040-901 Ribeirão Preto, SP, Brazil
}

\author{
Received 16 April 2011; Accepted 16 November 2011
}

\begin{abstract}
The present study evaluated the relative growth and allometry of Massartella brieni Lestage and Thraulodes sp. (Leptophlebiidae: Ephemeroptera). The morphometric analysis was based on 23 measurements and was conducted using a multivariate approach. Throughout postembryonic ontogeny, all of the head measurements, including those of the mouthparts, exhibited negative allometric growth. The mesothorax and wing pad exhibited positive allometric growth. The hind legs lengths in M. brieni and the fore and hind legs lengths in Thraulodes sp. exhibited positive allometry. The abdominal length in these two species exhibited positive allometric growth. Positive allometry was also observed along the abdomen width for M. brieni, and isometry was observed for Thraulodes sp. The relative strengthening of the thorax (in preparation for the winged stage) and the relative increase in the abdomen (which may be related to the development of the reproductive structures) during growth indicate that many of the structures that exhibit positive allometric growth are related to the transition from the aquatic to the adult stage of development.
\end{abstract}

Key words: Lotic environments / allometry / aquatic insects / morphometrics / multivariate allometry

\section{Introduction}

Insects display great functional, morphological and species diversity. Part of morphological variability observed in insects can be associated with the allometry (variation of morphological traits associated with the variation of body size). The allometry can be viewed on three different perspectives, which are related to growth (ontogenetic allometry), individual variability (static allometry) and phylogeny (phylogenetic or evolutionary allometry) (Klingenberg and Zimmermann, 1992a). Ontogenetic allometry is the variation in relative size of traits with respect to body size during development; static allometry is the variation in relative size of traits of the individuals of the same species after completing growth or during a specific stage in development; and phylogenetic or evolutionary allometry is the relative size of different traits among individuals of different species or lineages at the same stage of development (Klingenberg and Zimmermann, 1992a; Klingenberg,

\footnotetext{
*Corresponding author: pcbispo@gmail.com
}

1996, 1998; Shingleton et al., 2007). Thus, morphological changes related to different types of allometry may amplify the morphological differentiation that is commonly observed among the individuals of different ages, casts, sexes, populations, species or evolutionary lineages in insects.

In low and medium order mountain streams of Intervales State Park, located in the Atlantic Rainforest biome, Massartella brieni and Thraulodes sp. (Ephemeroptera: Leptophlebiidae) are two common and abundant species, so they represent interesting material to test hypothesis about relative growth and ontogenetic allometry in insects. Among the Ephemeroptera, the Leptophlebiidae family has a large functional and morphological diversity. This family exhibits a large geographic distribution, with its maximum diversity being represented in the southern hemisphere (Da-Silva et al., 2002). In Brazil, this family is represented by 22 genera, including Massartella and Thraulodes. M. brieni is a species that characteristically occurs in pools mesohabitats, whereas Thraulodes sp. in riffles.

In the present study, 23 body measurements of each individual of M. brieni and Thraulodes sp. were obtained 
with the aim to evaluate and compare the relative growth and ontogenetic allometry of these two species. The expected results could be predicted based on general patterns of growth observed in insects (Clifford, 1970; Klingenberg and Zimmermann, 1992b; Jander and Jander, 1994; Teuscher et al., 2009) and on the function of the developing body parts. Thus, it was possible to make the following predictions: (a) small modifications in the relative growth rate of several body structures will amplify the morphological differentiation between $M$. brieni and Thraulodes sp. during growth; (b) the head measurements in both species will exhibit negative allometry, following the pattern observed in many insect species (Klingenberg and Zimmermann, 1992b; Rodrigues et al., 2005); (c) strengthening of the thorax muscles will occur in preparation for the winged stage, which will lead to positive allometry mainly in the mesothorax (Clifford, 1970); (d) the relative elongation of legs, mainly in the femur and tibia lengths (positive allometry), will be observed in both species following the usual pattern for insects (Teuscher et al., 2009); and (e) during growth, the abdomen will exhibit positive allometry in both species as a result of preparation for the reproductive stage (Clifford, 1970).

\section{Materials and Methods}

In the present study, the specimens were collected from five streams (first-fourth order, sensu Sthraler, 1957) in the Intervales State Park $\left(24^{\circ} 12^{\prime}-24^{\circ} 25^{\prime}\right.$ south latitude and $48^{\circ} 03^{\prime}-48^{\circ} 30^{\prime}$ west longitude) located in the Paranapiacaba Mountains in the State of São Paulo, among the municipalities of Ribeirão Grande, Eldorado, Guapiara, Iporanga and Sete Barras. The majority of the material was collected monthly between May 1999 and September 2000 using a Surber sampler $(0.250 \mathrm{~mm}$ mesh).

A total of 61 individuals of $M$. brieni and 74 of Thraulodes sp. with different sizes were analysed. Only females were measured to avoid morphometric differences related to the sexual dimorphism. The morphometric analysis was based on 23 variables, which were photographed in a stereoscopic microscope and measured using a morphometric software. The following morphometric variables were obtained. For the head, distance between mid-anterior margin of clypeus and furcation of ecdysial suture, distance between lateral ocelli, distance between eyes, clypeus width, eye length, labium width, maxilla size and mandible size were measured. For the thorax, prothorax width, prothorax length, wing pad length, mesothorax width and mesothorax length were measured. For the legs, fore femur length, fore femur width, fore tibia length, fore tarsus length, hind femur length, hind femur width, hind tibia length and hind tarsus length were measured. For the abdomen, abdomen length and tergum VII width were measured (Fig. 1).

The morphometrics variables were log-transformed before the analysis. Canonical discriminant analysis was used to obtain the scores of the individuals of two species in a discriminant space. An ANCOVA based on these scores was used to test the differences between the species and the interaction with the generalized body size (first axis of principal component analysis using the criterion of variance-covariance).

The allometric growth of the nymphs was evaluated using a principal component analysis (Legendre and Legendre, 1998) and Jolicouer's multivariate allometric coefficient (Jolicouer, 1963). Coefficients that are larger than one are considered to be representative of positive allometry, those smaller than one are considered to be representative of negative allometry, and those equal to one are isometric. A positive allometry indicates that a given structure grows at a higher rate than generalized body size (first axis of principal component analysis), whereas a negative allometry indicates that the structure grows at a shorter rate (Monteiro, 1997). The confidence intervals of the multivariate allometric coefficients estimates were obtained using the bootstrapping method. The multivariate allometric coefficients were calculated using the PAST (Hammer et al., 2001).

\section{Results}

The two studied species in the present paper were morphometrically different (Table 1). In addition, interaction between the species and the generalized size was observed, indicating that the morphometric differences between them were amplified during growth (Table 1; Fig. 2). The morphometric data for $M$. brieni and Thraulodes sp. indicated that the majority of the morphometric variables exhibited allometric growth. The multivariate allometric coefficients for each variable, with the respective confidence intervals $(95 \%)$, for the two species are shown in Fig. 3. The body structures with Jolicouer's allometric coefficients less than 1 (below the line) exhibited negative allometry, those structures with a coefficient greater than 1 (above the line) exhibited positive allometry, and those with a coefficient equal to zero (confidence interval overlapping the line) exhibited isometry (Fig. 3).

The data demonstrate changes in the body proportions in M. brieni and Thraulodes sp. during growth. In this regard, the structures exhibited the following patterns: (1) for the head, all of the measurements, including those of the mouthparts, exhibited negative allometric growth; (2) for the thorax, the two species exhibited the same growth pattern. The prothorax exhibited positive allometric growth for its width and negative growth for its length; the mesothorax exhibited positive allometric growth in the width, length and wing pad; (3) for the fore legs, negative allometry was observed for the femur width and the tarsus length in both species; the tibia and femur lengths in $M$. brieni exhibited isometric growth, whereas those in Thraulodes sp. exhibited positive allometric growth; (4) for the hind legs, negative allometric growth was observed for the femur width and the tarsus length in both species; the femur and tibia lengths exhibited positive allometric 
Table 1. ANCOVA of the scores for individuals of the Massartella brieni and Thraulodes sp. (species), using the generalized body size (first axis of the principal component analysis, PC1) as a covariate. The scores were obtained using canonical discriminant analysis. SS: Sum of Squares; DF: Degrees of Freedom; MS: Mean Squares.

\begin{tabular}{llllrr}
\hline Effect & SS & DF & MS & $F$ & $P$ \\
\hline Species & 1302 & 1 & 1302 & 2603 & 8 \\
PC1 & 4 & 1 & 4 & 0.001 \\
Species $\times$ PC1 & 63 & 1 & 63 & 127 & $<.005$ \\
\hline
\end{tabular}

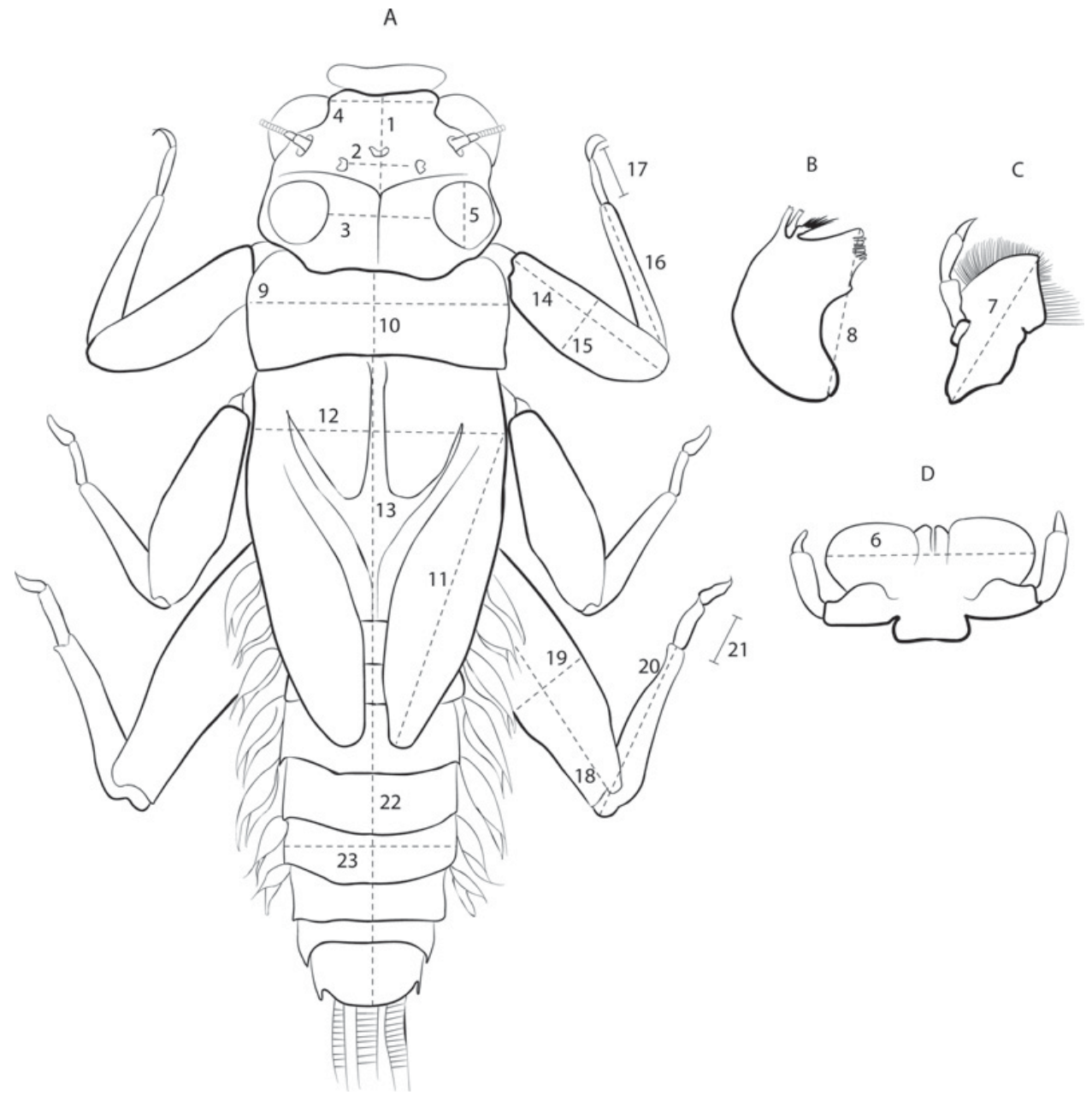

Fig. 1. Dorsal view of body and mouthparts of a nymph Thraulodes sp. (modified from Domínguez et al., 2006) with the 23 body measurements used to evaluate the growth: (1) distance between the midanterior margin of clypeus and furcation of ecdysial suture, (2) distance between lateral ocelli, (3) distance between eyes, (4) clypeus width, (5) eye length, (6) labium width, (7) maxilla size, (8) mandible size, (9) prothorax width, (10) prothorax length, (11) wing pad length, (12) mesothorax width, (13) mesothorax length, (14) fore femur length, (15) fore femur width, (16) fore tibia length, (17) fore tarsus length (18) hind femur length, (19) hind femur width, (20) hind tibia length, (21) hind tarsus length, (22), abdomen length and (23) tergum VII width.

growth in both species; (5) for the abdomen, the two species exhibited positive allometric growth for length; for tergum VII, M. brieni exhibited positive allometric growth, whereas Thraulodes sp. exhibited isometric growth.

\section{Discussion}

The morphological diversity that is observed in animals may result from different processes, from phylogenetic restrictions to adaptive pressures. Small changes during ontogeny as a result of heterochronic and allometric processes can produce important morphological differences between related taxa (Manunz and German, 1997; Monteiro et al., 1997). Thus, it is expected that small differences in the growth rates among the different body parts can amplify differences among species during ontogeny. Therefore, our data agree with this expectation since the results revealed that the morphometric differentiation between the two species was amplified during growth.

In the present study, changes in the proportions of several body parts in $M$. brieni and Thraulodes sp. during growth were observed, since the majority of the measured 


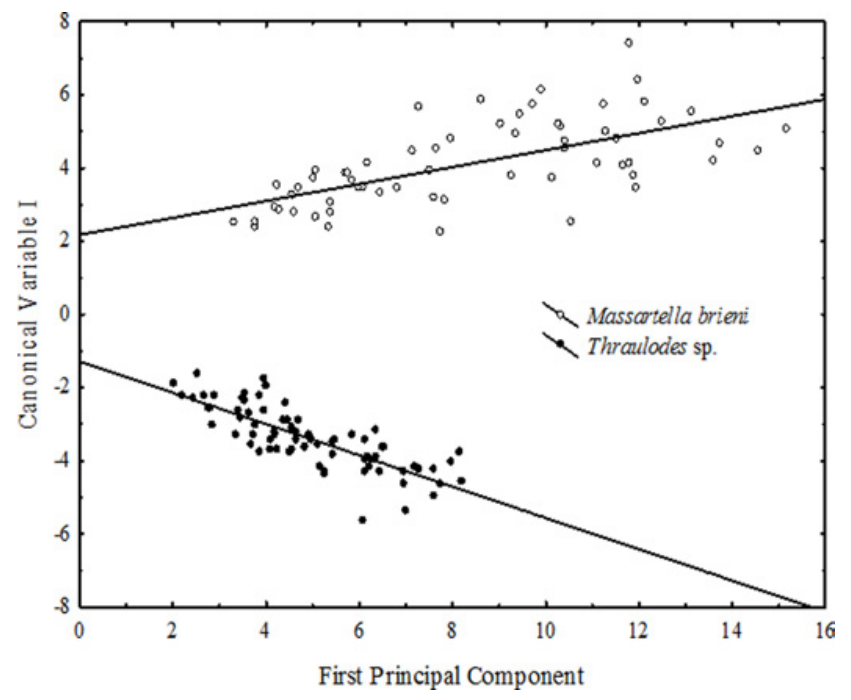

Fig. 2. Relationship between the scores and the generalized size (first principal component) in individuals of the species Massartella brieni and Thraulodes sp. The scores were obtained using canonical discriminant analysis.

structures exhibited allometric growth. For the head, all of the morphometric traits, including the mouthparts, exhibit negative allometry, confirming our initial hypothesis. This is a common pattern and has been reported frequently (Klingenberg and Zimmermann, 1992b; Jander and Jander, 1994; Rodrigues et al., 2005). Thus, the head of two studied species followed the pattern of growth of the majority of insects.

A potential explanation for the negative head allometry in the two evaluated species is the restriction that a small size may impose on the adjustment of the nervous system and in the acquisition of food. The heads of insects contain the nervous ganglia, the sensory system and the feeding parts (mouthparts). These structures must allow for the effective interaction of the insect with the external environment, even in juveniles. In this sense, according to Jander and Jander (1994), negative allometry of the sensory structures (the compound eyes and antennal sensilla) may reflect a need to maintain a minimal sensibility and sensorial resolution in juveniles (small) individuals. Thus, a proportionally larger head in small individuals may be necessary for these individuals to interact adequately with the environment.

The thorax of winged insects contains powerful muscles that are used to move the wings. Therefore, during a nymph's growth, it is expected that the muscles of this tagma, especially at the mesothorax and metathorax, are strengthened to prepare for the winged stage. For the two Ephemeroptera species, the thorax became more robust, the size of the wing pad and the mesothorax width and length exhibited positive allometry, indicating the strengthening of those structures that are related to flight (Clifford, 1970). In both species, the width of the prothorax exhibited positive allometric growth that
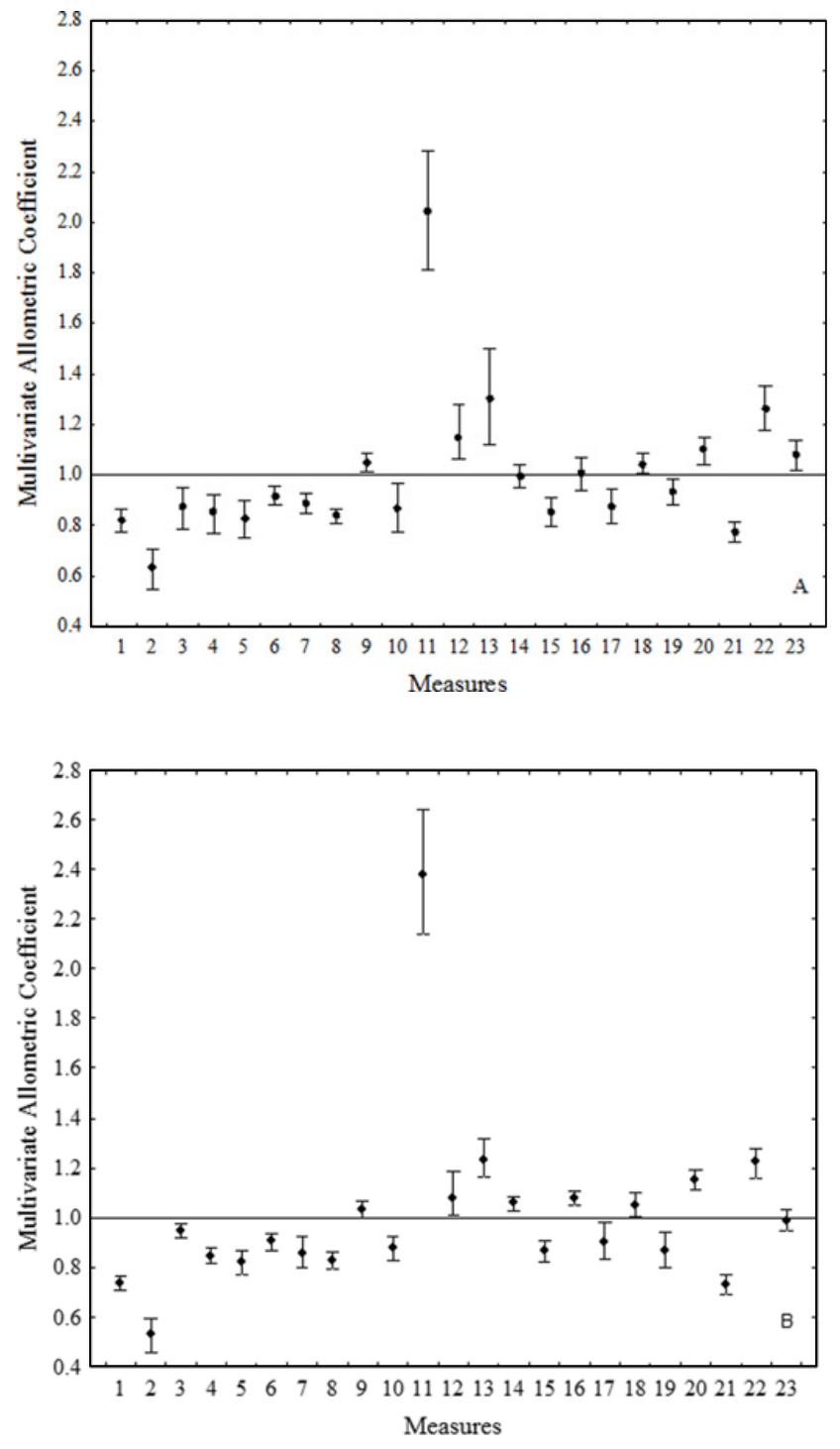

Fig. 3. Variation of the allometric coefficient for 23 measures (see caption of Fig. 1) of Massartella brieni (A) and Thraulodes sp. (B) collected in streams of Intervales State Park, State of São Paulo. Confidence interval of $95 \%$ obtained by the Bootstrap.

followed the same pattern as in the mesothorax; in contrast, the length of the prothorax exhibited negative allometric growth. This distinctive pattern to the prothorax length may be explained by the compression of this structure as a result of the positive allometric growth of the mesothorax.

The positive allometry of the legs relative to body size in insects is often observed (Teuscher et al., 2009). We observed that the tibia and femur lengths of the hind legs in M. brieni and of the fore and hind legs in Thraulodes sp. exhibited positive allometry. According to size-grain hypothesis (Kaspari and Weiser, 1999), the ability to perceive the texture of the substrate depends on the size of the legs because the irregularities seem to be smaller for individuals with larger legs. In this sense, smaller legs facilitate the interstitial movement, whereas larger 
legs aid in the locomotion across obstacles. According to size-grain hypothesis, natural selection would favor smaller legs in small individuals and larger legs in large individuals. This phenomenon could lead to positive allometry in the legs such as that observed in the present study.

The size-grain hypothesis has been supported by empirical data from several studies (Kaspari and Weiser, 1999; Espadaler and Gómez, 2001; Schoning et al., 2005). However, Teuscher et al. (2009) have verified that the species that use their legs mainly to move through a substrate, and the winged species, which barely use their legs for locomotion, may exhibit the same growth pattern (positive allometric growth of the legs); thus, their data do not support the size-grain hypothesis. Therefore, despite the positive allometric growth that has frequently been observed in legs of insects, the explanation is still controversial. We agree with Teuscher et al. (2009), who reported that the substrate rugosity is likely not the only factor involved in the positive allometry in legs and that other factors also need to be examined.

In both of the species that were examined in the present study, the measurements related to the abdomen revealed positive allometric growth of its length. In addition, the abdomen width exhibited positive allometric growth in M. brieni but not of that in Thraulodes sp., which was isometric. Thus, the abdomens of females of the two species grow at a higher rate than generalized body size. As adult Ephemeroptera have a short lifespan, the majority of female gametes complete their development in the last nymph stages prior to emergence (Clifford, 1970). Thus, the positive allometry of the abdomen size in the female nymphs during growth may be related to the development of reproductive structures (Gaino and Rebora, 2005; Fenoglio et al., 2007).

Although the two species occur in different mesohabitats (riffles and pools) and belong to different genera, they had similar growth patterns. The relative strengthening of the thorax (in preparation for the winged stage) and the relative increase in the abdomen (which may be related to the development of the reproductive structures) during growth are related to the transition from the aquatic to the adult stage. Thus, the data indicate that an important part of the morphological changes of the nymphs during ontogeny of M. brieni and Thraulodes sp. are related to the morphological adjustments to the transition to adulthood (Clifford, 1970).

Acknowledgements. G.P.P. thanks CNPq and CAPES, P.C.B. thanks CNPq (number 301652/2008-2) and S.S.C. thanks CAPES (PPG in Zoology, IBB, UNESP) for fellowships. P.C.B. thanks FAPESP (numbers 98/11074-3; 02/07216-4 and 04/09711-8) and CNPq (numbers 473246/2004-0 and 477349/ 2007-2) for constant support. A portion of this work was also supported by the FAPESP within the BIOTA Program (The Biodiversity Virtual Institute Program, http://www.biota.org.br, number 1998/05073-4). The authors thank Lucas S. Lecci for the drawings and Dr Elidiomar R. da Silva (UNIRIO) for assistance in the identification of studied taxa.

\section{References}

Clifford H.F., 1970. Analysis of a northen mayfly (Ephemeroptera) population, with special reference to allometry of size. Can. J. Zool., 48, 305-316.

Da-Silva E.R., Salles F.F. and Baptista M.S., 2002. As brânquias do gênero de Leptophlebiidae (Insecta, Ephemeroptera) ocorrentes no Estado do Rio de Janeiro. Biota Neotrop., 2, 1-4.

Domínguez E., Molineri C., Pescador M.L., Hubbard M.D. and Nieto C., 2006. Ephemeroptera of South America, Pensoft, Sofia-Moscow, $646 \mathrm{p}$.

Espadaler X. and Gómez C., 2001. Formicinae ants comply with the size-grain hypothesis. Funct. Ecol., 15, 136-139.

Fenoglio S., BO T. and Malacarne G., 2007. Allometric growth in Anacroneuria Klapálek 1909 nymphs (Plecoptera: Perlidae). Trop. Zool., 20, 109-114.

Gaino E. and Rebora M., 2005. Egg envelopes of Baetis rhodani and Cloeon dipterum (Ephemeroptera, Baetidae): a comparative analysis between an oviparous and an ovoviviparous species. Acta Zool., 86, 63-69.

Hammer O., Harper D.A.T. and Rian P.D., 2001. Past: Palaeonthological statistics software package for education and data analysis. Version. 1.37. Available online at: http:// palaeo-electronica.org/2001_1/past/issue1_01.htm

Jander U. and Jander R., 1994. Numerical allometric growth of the ommatidia, antennal sensilla, and teeth of foretibial combs in the milkweed bug Oncopeltus fasciatus Dallas (Heteroptera: Lygaeidae). Int. J. Insect Morphol. Embryol., 23, 329-344.

Jolicouer P., 1963. The multivariate generalization of the allometry equation. Biometrics, 19, 497-499.

Kaspari M. and Weiser M.D., 1999. The size-grain hypothesis and interspecific scaling in ants. Funct. Ecol., 13, 530-538.

Klingenberg C.P., 1996. Multivariate allometry. In: Marcus L.F., Corti M., Loy A., Naylor G.J.P. and Slice D.E. (eds.), Advances in Morphometrics, Plenum Press, New York, 23-49.

Klingenberg C.P., 1998. Heterochrony and allometry: the analysis of evolutionary change in ontogeny. Biol. Rev., 73, 79-123.

Klingenberg C.P. and Zimmermann M., 1992a. Static, ontogenetic, and evolutionary allometry: a multivariate comparison in nine species of waterstriders. Am. Nat., 140, 601620.

Klingenberg C.P. and Zimmermann M., 1992b. Dyar's rule and multivariate allometric growth in nine species of waterstriders (Heteroptera: Gerridae). J. Zool., 227, 453-464.

Legendre P. and Legendre L., 1998. Numerical Ecology: Developments in Environmental Modelling, Elsevier, Amsterdam, $853 \mathrm{p}$.

Manunz M. and German R.Z., 1997. Ontogeny and limb bone scaling in two New World marsupials, Monodelphis domestica and Didelphis virginiana. J. Morphol., 231, 117-130.

Monteiro L.R., 1997. Allometric growth and functional integration in the skull of black caiman Melanosuchus niger (Crocodyla: Alligatoridae). A jackknife approach. Rev. Bras. Biol., 57, 31-37.

Monteiro L.R., Cavalcanti M.J. and Sommer III H.J.S., 1997. Comparative ontogenetic shape changes in the skull of 
Caiman species (Crocodylia, Alligatoridae). J. Morphol., 231, 53-62.

Rodrigues D., Sanfelice D., Monteiro L.R. and Moreira G.R.P., 2005. Ontogenetic trajectories and hind tibia geometric morphometrics of Holymenia clavigera (Herbst) and Anisoscelis foliacea marginella (Dallas) (Hemiptera: Coreidae). Neotrop. Entomol., 34, 769-776.

Schoning C., Kinuthia W. and Franks N.R., 2005. Evolution of allometries in the worker caste of Dorylus army ants. Oikos, 110, 231-240.
Shingleton A.W., Frankino W.A., Flatt T., Nijhout H.F. and Emlen D.J., 2007. Size and shape: the developmental regulation of static allometry in insects. BioEssays, 29, 536-548.

Sthraler H.N., 1957. Quantitative analysis of watershed geomorphology. Am. Geophys. Union Trans., 33, 913-920.

Teuscher M., Brandle M., Traxel V. and Brandl R., 2009. Allometry between leg and body length of insects: lack of support for the size-grain hypothesis. Ecol. Entomol., 34, 718-724. 